\title{
Power Quality Application of Hybrid Drivetrain
}

\author{
A. Rassõlkin*, H. Hõimoja** \\ * Tallinn University of Technology (Estonia) \\ ** Ecole Polytechnique Fédérale de Lausanne (Switzerland) \\ anton.rassolkin@tptlive.ee,hardi.hoimoja@epfl.ch
}

\begin{abstract}
This paper presents a study on the power conditioning features of hybrid powertrain, especially regarding diesel-electric locomotives. Equipped with an embarked energy buffer for diesel generator support and utility grid interface, such a locomotive can be considered as a plug-in series hybrid vehicle. The driveline inductive components, like generator and motor windings and capacitive components like dc link capacitors can be used to provide STATCOM functions, and the energy buffer can be used for short-term grid support. The co-action of power electronics circuitries and diesel generator gives a possibility to observe the locomotive as a mobile versatile power plant for special rolling stock and emergency supply. With high power levels ranging from few hundred kilowatts to several megawatts, the locomotives can participate in large-scale power conditioning at standstill, bringing revenues to the operators even "off-line".
\end{abstract}

Index Terms-hybrid power systems, power grids, power quality, railway engineering.

\section{INTRODUCTION}

Limited oil reserves and climate change are very popular topics nowadays. There is a great deal of debate about rejecting the Internal Combustion Engine (ICE) and replacing it with environment friendly electric motor (EM). The main challenge of such renovation is a battery capacity. At the moment, technology has not advanced enough to fully replace ICE with EM, in that case Hybrid Electric Vehicles (HEVs) present a very enticing solution. HEV represents a combination of two traction systems, based on HEV and EM topology, as a result, increasing of the total efficiency factor of the vehicle. Even more interesting seems the Plug-in Hybrid Electric Vehicle (PHEV) technology, which provides HEV connection to electrical grid. Such connection maintains a number of electric energy's advantages by fully charging the battery from the AC grid before each travel: the battery becomes more cost-effective, more fuel is saved and the carbon oxide emissions are also reduced [1]. Moreover, connection PHEV to electrical grid makes it a part of a smart electrical grid, meaning that the PHEV battery could be used as energy storage equipment in plug-in mode or as a STATic synchronous COMpensator (STATCOM) for power factor improvement. High power factor value means that the electrical grid is free from reactive current, resulting in less in grid energy loss and finest wires in equipment.

The diesel-electric locomotive by's it structure is close to series HEV, but more powerful, by several megawatts. If the diesel-electrical locomotive were to be connected to grid (Locomotive-to-Grid - L2G) it would assume new applications. Such a connection to AC grid would allow the locomotive's batteries to charge directly from the grid, which would be more environmentally friendly. Moreover, existence of energy storage elements, such as fuel tanks and battery packs, means that plug-in locomotive system could be used as a portable power plant.

\section{STRUCTURE OF DIESEL-ELECTRICAL LOCOMOTIVE}

In the Fig. 1 the typical structure of a diesel-electrical locomotive is presented. Diesel engine DE produces the rotating kinetic energy by burning the diesel fuel. Synchronous generator SG converts that kinetic energy into electric energy. Also, the synchronous generator is used as motor for soft start of the diesel engine. Synchronous generator feeds the traction motors TM through power electronic devices PE. They are required for changing the parameters of electric energy and provide traction motors controlling features. The battery pack BAT is used for storing electrical energy generated by synchronous generator and produced by traction motors in regenerative braking mode as well.

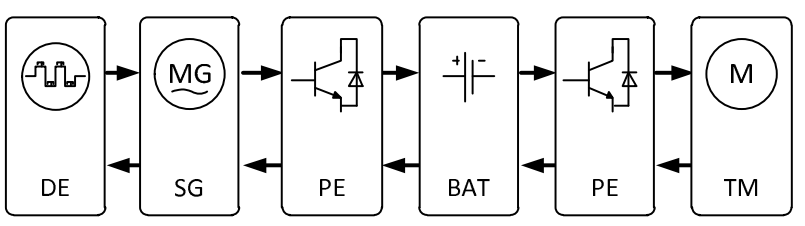

Fig. 1. The structure of diesel-electrical locomotive.

Diesel engine is an ICE and it means it has a list of disadvantages. The power factor of internal combustion engine is very low and the product of combustion is carbon dioxide $(\mathrm{CO} 2)$ and carbon monoxide $(\mathrm{CO})$, which is environmentally unfriendly. There are some alternative energy sources which already exist and can replace ICE as primary energy source.

A fuel cell is an electrochemical device that produces electricity by means of a chemical reaction from hydrogen, their fundamental is much like a battery, but some reservoirs for hydrogen storing are required. In comparing with traditional ICE the power factor of fuel cells are higher and they are environmentally friendly.

One interesting solution for primary energy source can be molten salt batteries. One of the latest designs are Zebra batteries operate at high temperature $\left(250{ }^{\circ} \mathrm{C}\right.$.. 350 $\left.{ }^{\circ} \mathrm{C}\right)$ and utilize molten sodium aluminumchloride (NaAlCl4). The energy density of Zebra batteries is high. Moreover they have high efficiency; low self-discharge on the operation mode, but using ca $15 \%$ of its own 
capacity per day to maintain temperature when not beeing in use.

As an additional energy source an electric double-layer capacitor (EDLC), or just supercapacitor could be used. Supercapacitor is a capacitor with a high energy destiny, with a capacitance up to kilo Farads. They have significantly short charging/discharging and could be used for the smooth start-up of electric motor, to reduce the voltage peaks. On one hand the supercapacitor has high efficiency, low self-discharge, long life lifetime and low cost per cycle. From the other, low voltage of single device, usually they are used to be connected in series that decreases the total capacity.

\section{STATCOM}

The balance between energy generation and consumption of active and reactive power is one of the main demands of electric power quality analysis. When balance is lost, frequency and voltage values may surpass their limits. The traditional reactive power compensators, much like capacitor batteries and synchronous compensators, have several disadvantages. STATCOM presents a new solution, based on power electronics.

There are some different circuit designs for STATCOM, but they generally have the same configuration. The STATCOM is based on a solid-state voltage source converter (VSC in the Fig. 1), implemented with an inverter and connected in a shunt with the power system through a coupling reactor (XL in the Fig. 1) [2]. The reactor $\mathrm{XL}$ is connected in order to provide harmonic minimization. The main configuration of STATCOM is presented in Fig. 1, where $\mathrm{C}$ is a DC capacitor. The power flows are shown with arrows. Since the dc capacitor is not a bulk energy storage device, the STATCOM does not have the ability of active power compensation [3]. With connection the battery to DC capacitor the STATCOM gets ability for booth, active and reactive, power compensation.

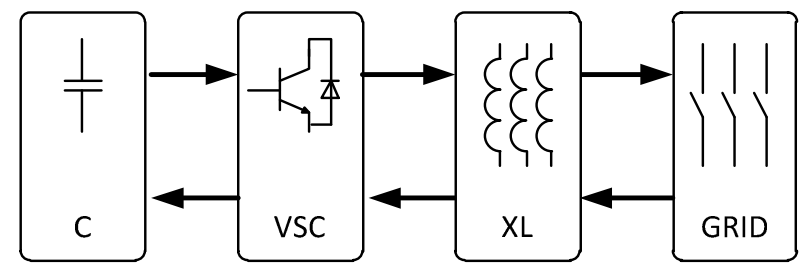

Fig. 1. Basic configuration of STATCOM

Mathematically the active power P of the STATCOM can be predicted by equation (1) and reactive power $\mathrm{Q}$ according to (2)

$$
\begin{aligned}
& P=\frac{U_{V S C} U_{\text {grid }}}{X_{L}} \sin \gamma \\
& Q=\frac{U_{V S C} U_{\text {grid }}}{X_{L}} \cos \gamma-\frac{U_{\text {grid }}^{2}}{X_{L}}
\end{aligned}
$$

where $\mathrm{U}_{\mathrm{VSC}}$ is voltage magnitude of the voltage source inverter; $\mathrm{U}_{\text {grid }}$ is a grid's voltage magnitude; $\mathrm{X}_{\mathrm{L}}$ reactance of coupling reactor; $\gamma$ is phase difference between the voltages.

As can be seen from equations (1) and (2), changing a voltage magnitude with a voltage source converter allows using STATCOM in different operation modes. The operation modes of STATCOM are presented in Fig. 2.

As shown in, Fig. 2.a, the voltage magnitude of STATCOM U $U_{V S C}$ is equal to grid's voltage magnitude $\mathrm{U}_{\text {grid, }}$, and the device operates in no-load operation mode. The STATCOM could be used as a portable power plant or Uninterruptible Power Supply (UPS).

STATCOM operates in capacitive operation mode (Fig. 2.b) when the voltage magnitude of STATCOM U $U_{\mathrm{VSC}}$ is higher than grid's voltage magnitude $U_{\text {grid }}$ and the current through the coupling reactor $\mathrm{I}_{\mathrm{xl}}$ becomes leading.

If current $\mathrm{I}_{\mathrm{x}}$ lags, the grid's voltage magnitude $\mathrm{U}_{\text {grid }}$ would be higher than the voltage magnitude of STATCOM $U_{V S C}$, and device would operate opposite to previous mode as a reactor with controllable inductive reactance. In that case, the STATCOM operates in inductive operation mode (Fig. 2.c).

a)
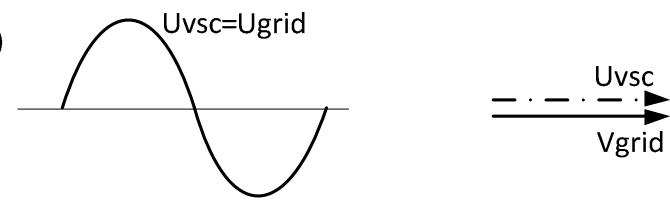

b)
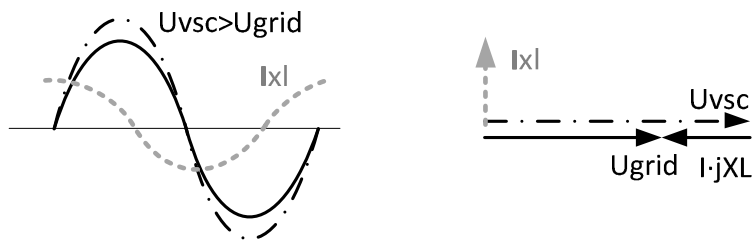

c)
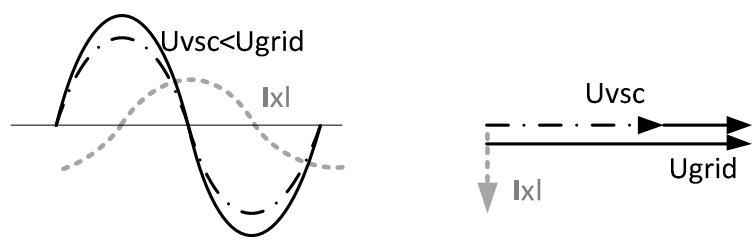

Fig. 2. Operation modes of STATCOM.

With STATCOM, a number of valuable benefits can be attained in power systems: dynamic voltage control, increased power transmission capability, and stability of long power corridors; facilitating connection of renewable generation by maintaining grid stability and fulfilling grid codes, and facilitating the building of high speed rail; maintaining power quality in grids dominated by heavy industrial loads such as steel plants and large mining complexes; enabling the implementation of Smart Grids [4].

Connected to grid STATCOM may be used for different applications:

- Power factor correction;

- Asymmetrical load balancing;

- Voltage control;

- Active harmonics filtration;

- Flicker mitigation. 


\section{ACTIVE FILTER}

The power electronic devices used in STATCOM allow response on the grid's changing parameters without delay. That means that STATCOM could be used as an active filter in some application.

The main function of an active filter is to return the magnitude of parameter to sine wave. The filter performance of parallel active power filter does not depend on the power system impedance, and dynamic compensation of harmonic and reactive power can be achieved [5]. That is a difference with a passive LC filter that increases the impedance on a different frequency to block different harmonics. Only the main harmonic passes through, but other harmonics cannot be completely cancelled out. In some applications, low-pass and band bass-pass passive filters are used for low-order harmonic detection [6].

In the Fig. 3 basic operating principle of active filter is presented. The first diagram (Fig. 3.a) describes the source current shape, which is periodical and contains a high-order harmonics. The active filter produces the current $\mathrm{I}_{\mathrm{af}}$, (Fig. 3.b), which is opposite to harmonics and in sum with source current return the magnitude of the main harmonic. The current shape of the load is presented in Fig. 3.c, in ideal case it is pure sine wave.

In order to get optimum performance and to minimize influence to the loads, the active filter should be located as close as possible to the source of harmonics.

There are many causes of the non-sine curves and harmonic appearance - different switching process of parts of the electric grid. But the major issue of harmonics is diode rectifiers with smoothing dc capacitors that are used in electronic equipment, household appliances, and ac drives [7]. Because of this the harmonics can be divided to voltage-source harmonics and current-source harmonics, as well the active filters sorts by type of harmonics they reduced. Definitely, the type of used active filter depends on the character of the load and the type of distortion it produces. a)

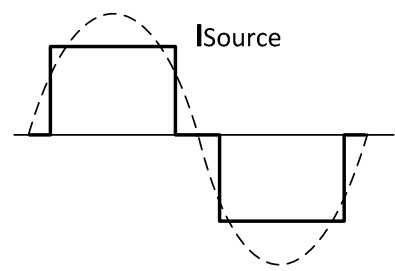

b)

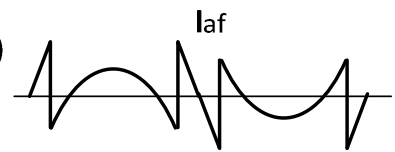

c)
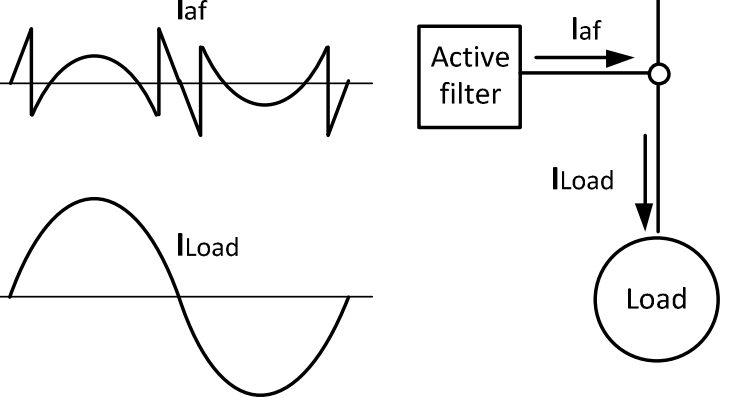

Fig. 3. Basic of active filter

\section{STATCOM IMPLEMENTATION INTO POWERTRAIN}

Using of STATCOM with changing load applications could be even more helpful, in that case a portable solution would be very interesting. The railway transport operations could be one of the applications for portable STATCOM devices.

A whole list of benefits emerges with connecting diesel electrical locomotive to the grid. Such a connection to the grid diesel-electric locomotive could be updated to be used as STATCOM. A possible solution is presented in Fig. 4. The traction synchronous generator $\mathrm{SG}$ is mechanically connected to diesel engine DE's shaft and usually used for producing electric energy to feed the traction motors of the locomotive. One side of the winding of synchronous generator (u1-v1-w1) is connected to voltage source converter VSC. The voltage source convertor is connected to traction system via filtering capacitor $\mathrm{C}$ and battery pack BAT.

The other side of the stator winding (u2-v2-w2) is connected to two contactors. The first contactor KM1 is required to provide $\mathrm{Y}$ connection for the stator winding of synchronous generator, when the locomotive operates in

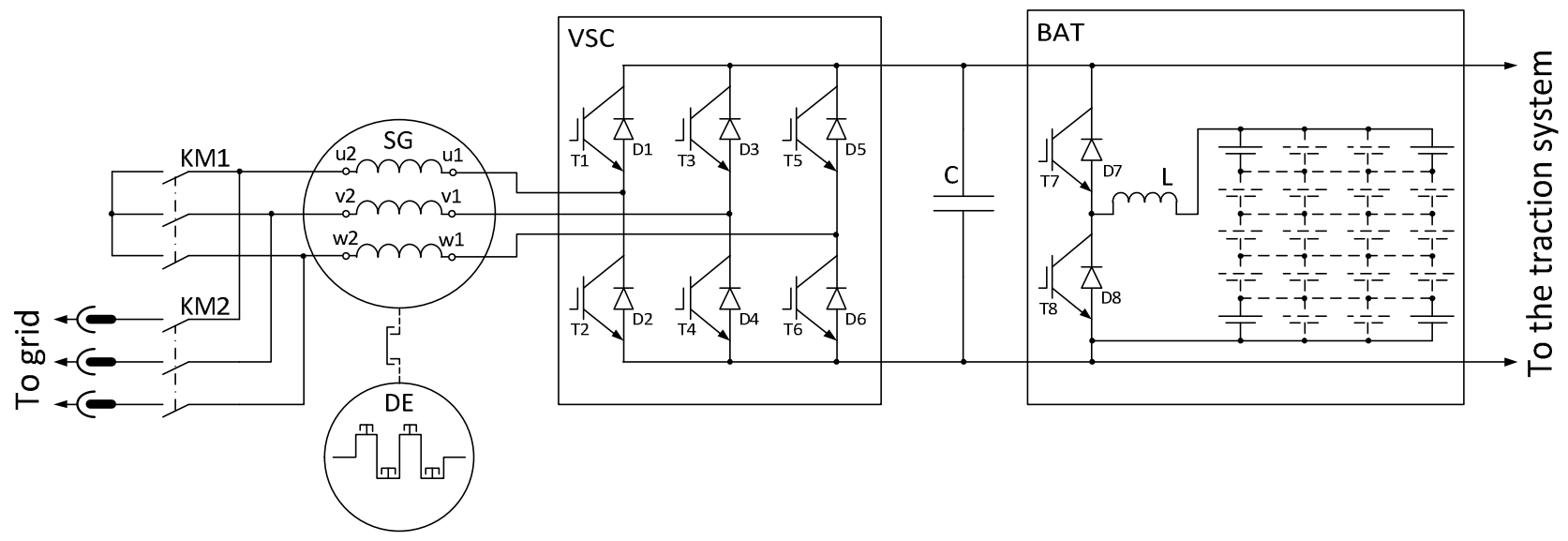

Fig. 4. STATCOM solution for hybrid powertrain. 
traction mode. Another contactor KM2 is required to connect the locomotive to the grid, when it operates in plug-in mode. In that case the stator winding of synchronous generator is used as a coupling reactor of STATCOM.

The railway's works are often concerned with welding operations. Repeatedly welding operations are the reason of harmonics. In case the implemented to powertrain STATCOM would operate as an active filter the produced by welding operations harmonics would be reduced. In this instance the active filtering device would be close to the harmonic source, which means the power grid would be free of harmonic noise.

One of the benefits of STATCOM's adapting to dieselelectrical locomotive is portability. Plug-in powertrain can be used directly in places where STATCOM operations are required.

\section{Portable Power Plant}

There has been much debate about the smart electrical grid and it implantation into today's electric network. One of the main points of the smart electrical grid is distributed energy production. The features of distributed energy production are energy transmission costs reduction and decreasing the high-voltage of transmission equipment, and, as result, reduction of energy losses and more environment friendly energy production. Moreover, the energy flow becomes more controllable, and energy balancing becomes easier.

The power output of diesel-electrical locomotives is usually in the range from hundred kilowatts to few megawatts. That is very noticeably for lot applications. A reserve of fuel stored in fuel tanks of diesel-electrical locomotive allows it to work for quite a long time. These facts promote to diesel-electric locomotive-to-grid (L2G) connection. That allows to use them as portable electrical energy plants.

As an alternative to plug-in powertrains a distributed superconducting magnetic electric storage (D-SMES) can be viewed. The D-SMES device is, in theory, a very simple idea and powerful tool for a power system planner [8]. SMES is a device that stores energy in the magnetic field produced by direct current in the overcooled to cryogenic temperature coil. The main drawback of SMES is very short storage time (up to a second), but, on the other hand, the charging/discharging time of SMES is very short. It allows their usage for covering the voltage spikes in electrical grid. Implanting SMES to the electrical grid allows utilities to improve system reliability and transfer capacity, giving costeffective grid stabilization for entire electric utility system [9]. Portable solutions of D-SMES application exist. The energy storage device is implanted to the trailer that connected to high voltage bus to control parameters of the grid.

\section{CONCLUSIONS}

Connection of vehicle to grid (V2G) is becoming more popular nowadays. Using electrical vehicles and hybrid electrical vehicles in connection with electrical grid brings new features to the electrical grid. Ability to use plug-in vehicle allows making the electrical grid more widely-distributed. Plugging-in more powerful vehicles, such as a powertrain, to the grid increases the range of its application.

- Using power electronic converters in powertrains allows using it as a STATic synchronous COMpensator. The main application of STATCOM is to compensate the reactive energy consumption.

- The fast energy flow control allows using the plug-in powertrain as parallel active filter. The main application of active filter is to regain the magnitude of parameter to sine wave and reducing harmonic influence.

- The diesel-electrical locomotive uses diesel fuel as it primary energy source and electric batteries as an additional energy storage source. That features allows implementing the plug-in powertrain as portable power plant.

There is no complex modernization required for plugging the diesel-electrical locomotive to the grid. Moreover, nowadays used powertrains can be updated.

\section{ACKNOWLEDGMENT}

This research work has been supported by The Estonian Ministry of Education and Research (Project SF0140016s11) and The Estonian Archimedes Foundation (project „Doctoral School of Energy and Geotechnology-II“).

\section{REFERENCES}

[1] De Sousa, L.; Silvestre, B.; Bouchez, B.: A Combined Multiphase Electric Drive and Fast Battery Charger for Electric Vehicles, Vehicle Power and Propulsion Conference (VPPC), 2010 IEEE , pp. 1 - 6, 2010

[2] Teleke, S.; Yazdani, A.; Gudimetla, B.; Enslin, J.; Castaneda, J.:Application of STATCOM for Power Quality Improvement, Power Systems Conference and Exposition (PSCE), 2011 IEEE/PES, pp. 1 - 6, 2011

[3] Kuiava, R.; Ramos, R.A.; Bretas, N.G.: Control Design of a STATCOM with Energy Storage System for Stability and Power Quality Improvements, IEEE International Conference on Industrial Technology, pp. 1 - 6, 2009

[4] Grünbaum, R.; Andreasson, L.: STATCOM for Improved Grid Stability and Power Transmission Capability, ABB AB - FACTS, SE-721 64 Västerås, Sweden

[5] Xiangning, X.; Yonghai, X.; Hao, L.; Yulong, M.: Experimental Study and Comparison of Hybrid Active Filter with Parallel Active Filter, The Fifth International Conference on Power Electronics and Drive Systems, Vol.1, pp. 566 - 571, 2003

[6] Libo, H.; Xiaozhong, L.; Lei, D.; Geng, Y.: An improved method for compensating of harmonics of voltage-source with parallel active power filter, International Conference on Electric Information and Control Engineering (ICEICE), pp. 1977 - 1982, 2011

[7] Peng, F. Z.: Application Issues of Active Power Filters, Industry Applications Magazine, IEEE, pp. 21-30, 1998

[8] Ross, M.; Borodulin, M.; Kazachkov, Y.: Using D-SMES devices to improve the voltage stability of a transmission system, Transmission and Distribution Conference and Exposition, Vol.2, pp. 1144 - 1148, 2001 IEEE/PES

[9] J. W. Martin, "D-SMES Application", Magnetics Magazine 